\title{
CAIXA DE SENSAÇÕES - ARTES VISUAIS NA PERSPECTIVA DO DESENHO UNIVERSAL PARA APRENDIZAGEM
}

\author{
BOX OF SENSATIONS - VISUAL ARTS IN THE PERSPECTIVE OF UNIVERSAL DESIGN FOR \\ LEARNING
CAJA DE SENSACIONES - ARTES VISUALES EN LA PERSPECTIVA DEL DISEÑO UNIVERSAL DE APRENDIZAJE

\author{
Eva Bernadete Budniak Tozato \\ Mestranda em educação: teoria e prática de ensino- Universidade Federal do Paraná. \\ E-mail: eva.arte7@gmail.com. \\ Orcid: https://orcid.org/0000-0002-5538-2582
}

\author{
Anderson Roges Teixeira Góes \\ Doutor. Programa de Pós-Graduação em Educação: Teoria e Prática de Ensino e Programa de Pós- \\ Graduação em Educação em Ciências e em Matemática- UFPR. \\ E-mail: artgoes@ufpr.br. \\ Orcid: http://orcid.org/0000-0001-8572-3758
}

\author{
Rossano Silva \\ Doutor em educação. Programa de Pós-Graduação em Educação: Teoria e Prática de Ensino - UFPR. \\ E-mail: rossano.degraf@yahoo.com.br. \\ Orcid: http://orcid.org/0000-0003-1591-860X
}

\begin{abstract}
RESUMO
Esta pesquisa apresenta uma proposta de concepção, elaboração e aplicação de material didático na perspectiva do Desenho Universal para Aprendizagem (DUA), para a exploração tátil/sensorial da temperatura das cores. A intenção foi possibilitar o aprendizado a respeito deste tema de Artes Visuais por todos os estudantes, com ou sem deficiência visual, de uma turma de terceiro ano do Ensino Fundamental de uma escola da rede Municipal de Curitiba. Tal concepção de material didático justifica-se pela observação de uma necessidade emergente de sala de aula. Para a fundamentação foram utilizados referenciais para apresentação dos conceitos de Desenho Universal (DU) e Desenho Universal para Aprendizagem, documentos e leis que tratam da inclusão na educação brasileira, conceituação de temperatura das cores. Por apresentar os princípios do DU e do DUA, promovendo o acesso de todos os envolvidos ao tema de forma democrática e inclusiva, o material produzido atendeu às expectativas iniciais e, ainda, pôde ser utilizado para outras ações pedagógicas voltadas a aprendizagem referente a cores.
\end{abstract}

Palavras-chave: Educação inclusiva. Desenho universal. Artes visuais. Material didático.

\section{ABSTRACT}

This research presents a proposal for the conception, elaboration and application of teaching material from the perspective of Universal Design for Learning (UDL), for the tactile/sensory exploration of color temperature. The intention was to make it possible for all students, with or without visual impairment, to learn about this Visual Arts theme, from a third-year elementary school class at a school in the Municipality of Curitiba. Such conception of didactic material is justified by the observation of an emerging need for the classroom. For the reasoning, references were used to present the concepts of Universal Design (UD) and Universal Design for Learning, documents and laws that deal with inclusion in Brazilian education, conceptualization of color temperature. By presenting the principles of DU and DUA, promoting access by 
all involved to the theme in a democratic and inclusive manner, the material produced met initial expectations and could also be used for other pedagogical actions aimed at color-related learning.

Key-word: Inclusive education. Universal design. Visual arts; Teaching material.

\section{RESUMEM}

Esta investigación presenta una propuesta para la concepción, elaboración y aplicación de material didáctico desde la perspectiva del Diseño Universal para el Aprendizaje (DUA), para la exploración táctil / sensorial de la temperatura del color. La intención fué hacer posible el aprendizaje por todos los estudiantes, con o sin discapacidad visual, sobre este tema de Artes Visuales, en una clase de escuela primaria de tercer año en la ciudad de Curitiba. Tal concepción del material didáctico se justifica por la observación de una necesidad emergente en el aula. Para los fundamentos teoricos se utilizaron referencias que presentan los conceptos de Diseño Universal (DU) y Diseño Universal para el Aprendizaje, documentos y leyes que abordan la inclusión en la educación brasileña, la conceptualización de la temperatura del color. Como presentan los principios de DU y DUA, promoviendo el acceso de todos los involucrados al tema de una manera democrática e inclusiva, el material producido cumplió con las expectativas iniciales y, también, es possible usarse para otras acciones pedagógicas dirigidas al aprendizaje relacionado con el color.

PALABRAS-CLAVE: Educación inclusiva. Diseño universal. Artes visuales. Material didáctico.

\section{INTRODUÇÃO}

Esta pesquisa apresenta a concepção, elaboração e aplicação de material, na perspectiva do Desenho Universal para Aprendizagem (DUA), para a exploração tátil/sensorial da temperatura das cores. Tem intenção de possibilitar o aprendizado a respeito do tema de Artes Visuais “temperatura das cores” para todos os estudantes de uma turma de terceiro ano do Ensino Fundamental de uma escola da rede Municipal de Curitiba, em que há inclusão de uma criança com baixa visão.

A pesquisa e construção do referido material teve origem durante as aulas da disciplina de Educação Inclusiva e Desenho Universal, na qual foram discutidos os temas apresentados na disciplina. Assim, ao se deparar com uma necessidade emergente em sala de aula, surgiu a demanda de um trabalho pedagógico com um dos conteúdos de Artes Visuais de maneira acessível. Dessa forma, ao pensar em propostas metodológicas e/ou materiais com o conceito do DUA, é que esta pesquisa se solidificou.

Nas diretrizes curriculares do Ensino Fundamental de Curitiba (CURITIBA, 2006), o componente curricular Arte aborda, entre as demais linguagens artísticas, as Artes Visuais que, dentre seus vários elementos de estudo, contempla a cor como um dos elementos utilizados nas produções artísticas. 
Desta forma, entre os diferentes estudos que podem ser realizados no que se refere às cores, destaca-se, nesta pesquisa, a temperatura das cores, que segundo Ostrower, não é um assunto de fácil compreensão, pois envolve alguns conceitos abstratos:

\begin{abstract}
A relação com "temperaturas" cromáticas tem seu ponto de partida nas três cores básicas do arco-íris: azul, vermelho e amarelo. Delas, o azul é considerado a cor mais fria, ao passo que o vermelho e o amarelo são consideradas quentes (o vermelho ligeiramente mais quente do que o amarelo, por ser mais escuro e parecer mais denso). A razão de tal distinção não será difícil de acompanhar; ela se origina em experiências humanas elementares imemoriais. Assim, o vermelho e o amarelo são espontaneamente associados a calor, fogo, sol, enquanto o azul se associa a céu, gelo e frio. Do mesmo modo, deduz-se imediatamente que seu teor expressivo: as cores quentes conotando proximidade, densidade, opacidade, materialidade, e as frias, distâncias, transparências, aberturas, imaterialidade. (OSTROWER, 2013, p. 193).
\end{abstract}

A classificação de cores quentes e frias foi criada pelo psicólogo alemão Wilhelm Wundt (1832-1920) para designar as sensações que cada cor pode gerar no ser humano. As cores quentes são consideradas dinâmicas e estimulantes e estão associados à vitalidade, excitação, alegria e movimento; enquanto as cores frias são estáticas e suaves, com efeitos calmantes e tranquilizantes.

Ao considerar a temperatura das cores para o uso nas representações artísticas dos estudantes, as quentes: vermelho, amarelo, laranja, etc., podem ser associadas ao fogo, calor, sol; enquanto que as consideradas frias, azul, verde, violeta, são associadas a frio ou água.

Ao abordar tais temas com crianças cegas ou com baixa visão, isso se trona um desafio, já que a dificuldade em perceber as cores, tanto para utilização em suas produções quanto nas obras já produzidas é um complicador para a compreensão de alguns conceitos tão abstratos e subjetivos como este. Esse foi justamente o ponto de partida para a investigação desta pesquisa.

Com isso, este texto apresenta breve contextualização sobre a inclusão na educação brasileira, considerando as mudanças ocorridas no decorrer dos anos, e a descrição de algumas das leis criadas para efetivar o processo de inclusão e de respeito aos direitos de todas as pessoas com ou sem deficiências. Na sequência, apresenta-se a fundamentação a respeito da proposta do DU e do DUA e a possibilidade de implementação de materiais com o conceito DUA em Artes Visuais, na perspectiva da inclusão escolar que atenda a todos os estudantes. 
Na metodologia utilizou-se a pesquisa qualitativa com intervenção pedagógica, e nela delineia-se o percurso de concepção e confecção de equipamento intitulado "Caixa de Sensações" capaz de proporcionar experiências táteis, com sensações térmicas, para o reconhecimento/aprendizagem da temperatura das cores, conteúdo da disciplina de Artes Visuais.

A análise dos resultados foi realizada a partir de propostas de exploração do material produzido, da compreensão dos objetivos relacionados à disciplina de Artes Visuais, no que diz respeito à compreensão da temperatura das cores, seu reconhecimento e possível uso nas produções visuais dos estudantes.

O material foi testado por profissionais que atendem os estudantes do terceiro ano e pela aluna de inclusão desta turma, que motivou a pesquisa, bem como, por colegas sem deficiência visual. Além disso, a professora que atende a Sala de Recursos Multifuncionais da escola utilizou o material com alunos com autismo e deficiência intelectual, esta professora participou ativamente da pesquisa, orientando os estudantes durante a exploração do material e coletando os dados para a pesquisa.

\section{Percurso da inclusão na educação brasileira}

No Brasil, apesar de o atendimento às pessoas com deficiência já ter iniciativas isoladas anteriormente, passa a ser regulamentado a partir da Lei de Diretrizes e Bases da Educação Nacional - Lei n 4.024/61, que destaca o direito à educação para as pessoas excepcionais, de preferência no sistema geral de ensino (BRASIL, 1961). Na sequência, a Lei $\mathrm{n}^{\circ}$. 5.692/71 determina tratamento especial para alunos com deficiências e superdotados, o que acaba induzindo a inserção desses alunos em classes ou escolas especiais (BRASIL, 1971). Nesse ritmo, seguem-se outras iniciativas na tentativa de atendimento adequado, porém, na grande maioria, são ações voltadas ao atendimento individualizado e assistencialista, ainda muito longe da universalização da educação.

Com a Constituição Federal de 1988 a educação passa a ser definida como direito de todos, com igualdade de condições de acesso e permanência na escola, sendo a garantia desse direito dever do estado (BRASIL, 1988). São criados então muitos documentos, em nível nacional e mundial, que reforçam a importância do respeito aos direitos de aprendizagem para todos por meio de uma educação inclusiva, como: o 
Estatuto da Criança e do Adolescente - Lei nº 8.069/90; a Declaração Mundial de Educação para Todos (1990); a Declaração de Salamanca (1994); a Política Nacional de Educação Especial (1994). A partir de 1996, a Lei de Diretrizes e Bases da Educação Nacional $n^{\circ}$ 9.394/96, determina que as redes educacionais devem disponibilizar os recursos adequados para atendimento de todos os estudantes de forma igualitária (BRASIL, 1996).

Com o movimento para que todos os estudantes sejam atendidos pela escola regular e tenham garantia de um processo educativo que atenda suas necessidades, outros documentos e leis voltadas à integração/inclusão são criados, como: o Decreto n $^{\circ}$ 3.298, de 1999, que regulamenta a Lei $n^{\circ} 7.853 / 89$, dispões sobre a Política Nacional para a Integração da Pessoa Portadora de Deficiência, define a educação especial como uma modalidade complementar para auxiliar todos os níveis de ensino.

As Diretrizes Nacionais para a Educação Especial na Educação Básica, Resolução $\mathrm{CNE} / \mathrm{CEB} \mathrm{n}^{\circ}$ 2/2001, determinam a matrícula de todos os alunos na rede regular de ensino, reforçando que é papel da escola se adequar para atender a todos os estudantes com necessidades educacionais especiais, possibilitando-lhes condições para uma educação de qualidade (MEC, 2001).

Mesmo com o Plano Nacional de Educação (PNE), Lei $n^{\circ}$ 10.172/2001, apontando que a principal meta, para aquela década da educação, deveria ser uma escola inclusiva que atendesse toda a diversidade humana, ficam ainda evidentes as deficiências em promover o atendimento adequado a todos os estudantes, pois ainda falta, na prática, a conscientização da sociedade, a formação dos professores e a real acessibilidade e atendimento educacional especializado.

De acordo com Convenção da Guatemala (1999), Decreto n³.956/2001, as pessoas com deficiência têm os mesmos direitos humanos e liberdades fundamentais que as demais pessoas, sendo considerada discriminação qualquer diferenciação ou exclusão devido a uma deficiência, sendo que o caminho da educação para todos está na eliminação das barreiras que possam impedir ou dificultar o acesso à aprendizagem (BRASIL, 2001).

O Ministério da Educação cria, em 2006, o Programa Educação Inclusiva: direito à diversidade, com objetivo de garantir o acesso de todos à escolarização, ao atendimento educacional especializado e a promoção da acessibilidade (MEC, 2006). 
Atualmente, com a meta do atual Plano Nacional de Educação, Lei n 13.005, de 25 de junho de 2014 (PNE 2014-2024), de universalizar o atendimento escolar aos estudantes com deficiência, transtornos globais do desenvolvimento e altas habilidades ou superdotação, de preferência na rede regular de ensino, as escolas vêm tentando se adequar a essa legislação para atender com qualidade todos os estudantes, de forma equitativa e democrática (BRASIL, 2014).

Considerando os avanços na legislação, e a obrigatoriedade da matrícula de todos os estudantes no sistema regular de ensino, temos atualmente, estudantes incluídos nas escolas regulares. No entanto, essas leis e documentos, apesar de algumas já terem décadas de vigência, apontando para o direito da educação inclusiva por meio do atendimento igualitário para todos os estudantes, na prática, atualmente continua a acontecer uma educação especial focada nos estudantes com alguma deficiência, geralmente de forma individualizada. E, quando incluídos em salas regulares, são normalmente, atendidos de forma diferente dos demais, recaindo na exclusão. Ainda, é possível verificar certa resistência à inclusão no sistema regular de ensino, por parte dos profissionais, com essa realidade, porém outra parte dos professores e demais profissionais têm se mobilizado para o atendimento adequado, que contemple as necessidades educativas de todos os estudantes.

Desta forma, a pesquisa e a produção de materiais e metodologias inovadoras é uma necessidade emergencial para quem quer adequar o currículo e atender a todos os estudantes por meio da equidade e universalização do ensino. Nessa perspectiva de inclusão no ambiente escolar é necessário considerar o DUA, integrando objetos, tecnologias e/ou metodologias adequadas em prol de uma educação com equidade.

\section{Do Desenho Universal ao Desenho Universal para Aprendizagem}

O conceito de DU é um requisito fundamental para garantir a qualidade de vida de um indivíduo, tanto no ambiente público como no privado. Sua essência é certificar que todos, com ou sem deficiência, possam praticar suas ações cotidianas e utilizar o espaço de modo autônomo e seguro. Essa concepção é utilizada para referenciar objetos, equipamentos e estruturas físicas que possam ser utilizadas por todas as pessoas, independentemente da sua idade, estatura, condições físicas, deficiências. Dessa forma, 


\section{espaços e objetos pensados na perspectiva do DU servem para todos sem distinção}

(GABRILLI, 2007).

Antes de se chegar ao termo "Desenho Universal",

em 1961, países como Japão, EUA e nações europeias, se reuniram na Suécia para discutir como reestruturar e recriar o velho conceito que produz para o dito “homem padrão", que nem sempre é o "homem real”. Assim, esta primeira conferência internacional foi berço para que, em 1963, em Washington, nascesse a Barrier Free Design, uma comissão com o objetivo de discutir desenhos de equipamentos, edifícios e áreas urbanas adequados à utilização por pessoas com deficiência ou com mobilidade reduzida. Mais tarde, esse conceito - tomado com mais profundidade pelos Estados Unidos - ampliou seu foco e mudou de nome. Passou a ser chamado de Universal Design e se propôs a atender todas as pessoas, num aspecto realmente universal. (GABRILLI, 2007, p. 8-9).

No Brasil, o DU começa a ser discutido em 1980 com a finalidade de adequar os espaços para toda a população com alguma dificuldade de locomoção, como os idosos, crianças, deficientes, entre outros. De 1985 até 2004 foram criadas normas técnicas relativas à acessibilidade e democracia. Segundo Gabrilli, o DU foi criado

com o objetivo de definir um projeto de produtos e ambientes para ser usado por todos, na sua máxima extensão possível, sem necessidade de adaptação ou projeto especializado para pessoas com deficiência. (GABRILLI, 2007, p. 10).

\section{Assim, o DU engloba as tecnologias assistivas, vistos que estas são}

produtos, equipamentos, dispositivos, recursos, metodologias, estratégias, práticas e serviços que objetivem promover a funcionalidade, relacionada à atividade e à participação da pessoa com deficiência ou com mobilidade reduzida, visando à sua autonomia, independência, qualidade de vida e inclusão social. (GABRILLI, 2007, p. 22).

Para que um produto/projeto/ambiente esteja na concepção do DU, é necessário que possua os seguintes princípios:

IGUALITÁRIO: São espaços, objetos e produtos que podem ser utilizados por pessoas com diferentes capacidades, tornando os ambientes iguais para todos; ADAPTÁVEL: Design de produtos ou espaços que atendem pessoas com diferentes habilidades e diversas preferências, sendo adaptáveis para qualquer uso;

ÓBVIO: De fácil entendimento para que uma pessoa possa compreender, independente de sua experiência, conhecimento, habilidades de linguagem, ou nível de concentração;

CONHECIDO: Quando a informação necessária é transmitida de forma a atender as necessidades do receptador, seja ela uma pessoa estrangeira, com dificuldade de visão ou audição. Informação de fácil percepção ao receptador;

SEGURO: Para ser usado eficientemente, com conforto e com o mínimo de fadiga;

SEM ESFORÇO: Baixo esforço físico, para uso com conforto e com o mínimo de fadiga; 
ABRANGENTE: Que estabelece dimensões e espaços apropriados para o acesso, o alcance, a manipulação e o uso, independentemente do tamanho do corpo (obesos, anões etc.), da postura ou mobilidade do usuário (pessoas em cadeira de rodas, com carrinhos de bebê, bengalas etc.). (GABRILLI, 2007, p. 12-16).

O acesso físico vem sendo ampliado para todas as pessoas, porém, na educação, não se tem avanços significativos apenas com o acesso físico, mobiliário e equipamentos adequados, é preciso promover o acesso de todos os estudantes à aprendizagem. Dessa forma, a partir das ideias do DU, com a finalidade de eliminar ou diminuir as barreiras metodológicas para a aprendizagem, a fim de atender a todos os estudantes de forma igualitária, surge a perspectiva do DUA, que consiste na criação de estratégias para acessibilidade de todos aos processos educacionais (ZERBATO e MENDES, 2018).

A intenção do DUA é que todos possam aprender, com uso de materiais flexíveis, estratégias e técnicas que possibilitem ampliar a aprendizagem dos estudantes com ou sem deficiência, universalizando a construção do conhecimento, ou seja, eliminando possíveis barreiras pedagógicas (ZERBATO e MENDES, 2018). Assim, são consideradas as necessidades emergentes em sala de aula,

O DUA consiste em um conjunto de princípios baseados na pesquisa e constitui um modelo prático que objetiva maximizar as oportunidades de aprendizagem para todos os estudantes [...] tem como objetivo auxiliar os educadores e demais profissionais a adotarem modos de ensino de aprendizagem adequados, escolhendo e desenvolvendo materiais e métodos eficientes, de forma que seja elaborado de forma mais justa e aprimorados para avaliar o progresso de todos os estudantes [...] na perspectiva do DUA, o mesmo material pode ser utilizado por todos da sala de aula, de modo a beneficiar outros estudantes na compreensão dos conteúdos ensinados. (ZERBATO e MENDES, 2018, p. 150).

Na perspectiva do DUA, o professor busca desenvolver estratégias e metodologias que contribuam para o seu planejamento, considerando, não apenas os estudantes que têm alguma deficiência ou que necessitam de apoio individualizado, mas que atenda a todos os estudantes da sua sala de aula. Isso contribui para o processo formativo de todos os estudantes.

Os produtos (objetos, metodologias, processos, etc.), na perspectiva do DUA, cumprem, segundo Rose e Meyer (2002), três princípios: princípio do engajamento que favorece a participação de todos no processo de ensino e aprendizagem, sem distinção das deficiências que os indivíduos possam ter; princípio da representação em que são proporcionados diferentes formas de representação do conceito, seja pela linguagem 
visual, oral, escrita e sensorial; princípio da ação e expressão trazendo flexibilidade de demonstrações e diversidade na maneira de explorar as informações e atuações dos envolvidos em prol do conhecimento.

É nesse sentido que se se desenvolve o presente estudo, partindo de uma necessidade real, identificada dentro de uma sala de aula em turma de terceiro ano do Ensino Fundamental de uma escola da rede municipal de Curitiba, ao trabalhar o conteúdo "temperatura das cores" (cores quentes e frias) na disciplina de Artes Visuais.

\section{Metodologia}

Com a perspectiva de respeito e inclusão de todas as pessoas nos modelos educacionais contemporâneos, a educação para todos é uma ação emergente e que está diretamente vinculada a ação e conhecimento do professor. Sendo assim, considerando a ação docente e o contato com as mais diversas necessidades de aprendizagem dos estudantes no cotidiano escolar, é que surgem inquietações a respeito do ensino de Artes Visuais, por meio de uma ação que contemple os conceitos de DUA, uma vez que todas as crianças têm os mesmos direitos de aprendizagem, numa perspectiva de educação inclusiva.

A pesquisa realizada apresenta dados qualitativos e foi desenvolvida a partir de uma intervenção pedagógica, pois, a partir de uma necessidade observada em sala de aula houve o planejamento e implementação de um material que possibilitou mudanças/avanços no processo de aprendizagem dos estudantes e pela observação e registro foi possível a avaliação dos resultados (DAMIANI, et al., 2013).

Assim, "as pesquisas do tipo intervenção pedagógica são aplicadas, ou seja, têm como finalidade contribuir para a solução de problemas práticos" (DAMIANI et al., 2013, p. 58), sendo o presenciado nesta pesquisa, com o intuito de que todos possam aprender determinado conteúdo, a criação de um material acessível foi o ponto de partida, caracterizando assim a educação inclusiva.

Segundo Valente (2015, p. 182), "a educação inclusiva é uma ação política, cultural, social e pedagógica, desencadeada em defesa do direito de todos os alunos de estarem juntos, aprendendo e participando, sem nenhum tipo de discriminação." Portanto, cabe aos professores, que estão no contato direto com os estudantes, observarem as reais 
necessidades de cada um deles, dentro do contexto da sala, e desenvolver o planejamento das disciplinas que estão sendo propostas, pois

\begin{abstract}
A educação inclusiva destaca a inclusão sociocultural para todos os seres humanos, buscando minimizar a exclusão social e a segregação em espaços educativos específicos, desafios que atingem todo o sistema educacional formal e não formal. (COSTA e ARAUJO JUNIOR, 2018, p. 146).
\end{abstract}

Foi durante uma aula de arte, para o terceiro ano do Ensino Fundamental, de uma escola municipal de Curitiba, que surgiu a necessidade de buscar um caminho mais adequado e justo para o trabalho com as cores e suas características, pois uma das estudantes que frequenta essa turma tem baixa visão ${ }^{1}$ (será chamada de Estudante 1) , a professora informou que ela vê apenas algumas cores com muita dificuldade, mas adora desenhar e explorar as cores. Já faz isso utilizando recursos táteis para o desenho como massa de modelar, colas em relevo, barbante, entre outros.

A E1 reconhece algumas formas e as utiliza em suas produções, porém tem uma preocupação em utilizar cores que considera "adequadas" em seus desenhos, como pôde ser observado na representação de uma árvore realizada com massinha de modelar, buscando utilizar as cores correspondentes ao natural, como é possível ver na Figura 01.

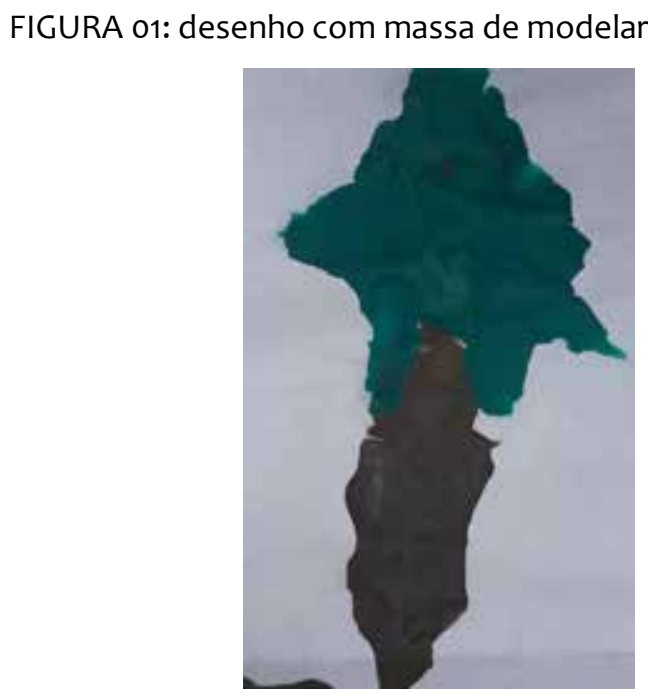

FONTE: os autores, 2020.

\footnotetext{
${ }^{1}$ Laudo médico atesta "Baixa acuidade visual", com cegueira e visão subnormal em um olho e perda não especificada da visão no outro olho.
} 
Sendo assim, a professora organizou alguns materiais táteis referentes à indicação das cores, conforme Figura 02.

FIGURA 02: E1 explorando o esquema de cores

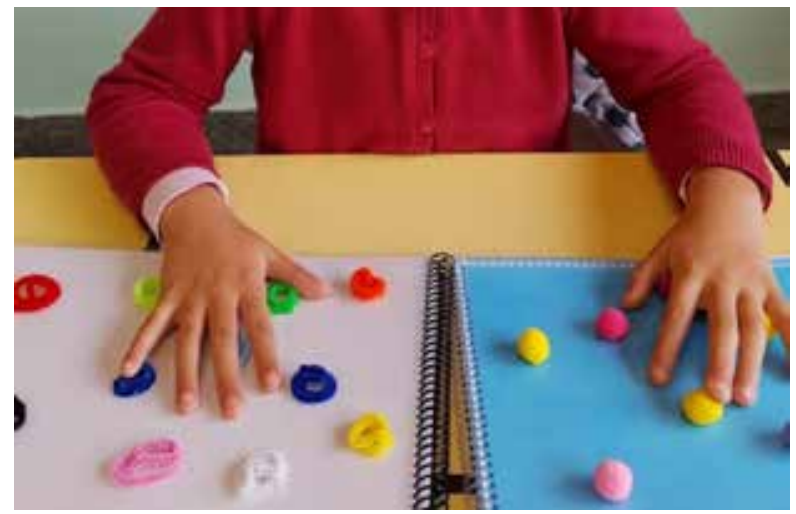

FONTE: os autores, 2020.

Porém, ao abordar o conteúdo de Artes Visuais, relacionado à temperatura das cores, a professora encontrou um desafio: a dificuldade ou impossibilidade de ver as cores com clareza inviabiliza ou dificulta o trabalho com esse conteúdo das Artes Visuais. Por isso, é necessário o uso de algumas estratégias metodológicas diferenciadas para conseguir proporcionar experiências sensoriais que contribuam para a formação de todos os estudantes.

Concordando com Zerbato e Mendes (2018, p. 151) “A maneira pela qual as informações são apresentadas aos estudantes pode expandir ou limitar seus conhecimentos, podendo demonstrar se eles vão ou não aprender o conteúdo". O trabalho com as cores, aparentemente fácil, envolve algumas especificidades que dificultam a percepção por algumas crianças. Nesse caso, "Quanto maior as possibilidades de apresentar um novo conhecimento, maiores serão as possibilidades em aprendê-Io" (ZERBATO e MENDES, 2018, p, 151).

Conforme relato da professora, para trabalhar com as cores quentes e frias, a mesma faz uso de copos com água morna e fria, coloridas adequadamente, para que tanto os colegas de turma que enxergam possam compreender a proposta quanto à referida aluna, porém, como a água logo esfria, a atividade precisa ser realizada de forma rápida e não há possibilidade de dispor por maior período de tempo o material aos estudantes. 
Em conversa com a professora regente, que atende a criança durante as aulas, e com a professora que atende no contraturno escolar, na sala de recursos multifuncionais, ficou evidente que, apesar de muitas estratégias já terem sido criadas e utilizadas, ainda existem algumas necessidades de metodologias e equipamentos específicos que possam contribuir, de forma mais efetiva, na aprendizagem dos estudantes. Metodologias e equipamentos que possam, de modo geral, considerar todas as suas necessidades e contemplar a superação de suas limitações, principalmente no que se refere às especificidades dos conteúdos das Artes Visuais. Assim, surge a necessidade de construção de um equipamento que possibilite a exploração sensorial a respeito das cores quentes e frias e que possa ser utilizado pela turma toda.

Considerando o envolvimento lúdico dos estudantes e o interesse que eles têm por propostas diferenciadas, definiu-se que o material a ser desenvolvido seria uma caixa se sensações, contemplando os princípios do DUA uma vez que este

\begin{abstract}
pode ser um aliado em potencial do trabalho colaborativo para o favorecimento da inclusão escolar, pois converge em um objetivo comum: a construção de práticas pedagógicas acessíveis para a escolarização de todos em sala de aula do ensino comum por meio da parceria colaborativa entre professor de ensino comum e Educação Especial e/ou outros profissionais especializados. (ZERBATO e MENDES, 2018, $p, 154)$
\end{abstract}

Portanto, trabalhar com cores por meio desse material é relevante para a inclusão de todos os estudantes com ou sem deficiência visual, uma vez que possibilita o aprendizado, tanto de forma visual, quanto tátil, proporcionando para todos os estudantes envolvidos a possibilidade de experimentação sensorial, envolta em ludicidade e brincadeira.

\title{
O processo de construção da Caixa de Sensações
}

A elaboração da Caixa de Sensações considerou a dificuldade de recursos da escola pública e o projeto foi pensado com materiais de baixo custo e acessíveis adquiridos pela pesquisadora. Assim, o processo de construção da Caixa de Sensações parte da elaboração de uma caixa de madeira reaproveitada, materiais para a confecção, como: tintas acrílicas nas cores branca, azul, verde claro, verde escuro, roxo, vermelho, laranja, amarelo e rosa, gesso, pedaços de metal, manta térmica, material térmico que 
aquece ao ser ligado em fonte de energia, papel, papelão e acetato. Na parte superior da caixa foram vazadas oito circunferências, todas do mesmo tamanho, sendo que em quatro delas foram colocadas, aleatoriamente, placas pintadas com tinta acrílica nas cores consideradas frias: azul, roxo, verde claro e verde escuro; enquanto que nos furos restantes foram colocadas placas pintadas com as cores consideradas quentes: vermelho, laranja, rosa e amarelo. Dentro da caixa foi elaborado um cuidadoso esquema de isolamento térmico sob as cores frias e de aquecimento, por meio de uma fonte de calor alternativa (uma cinta térmica), sob as cores quentes. (FIGURA 03)

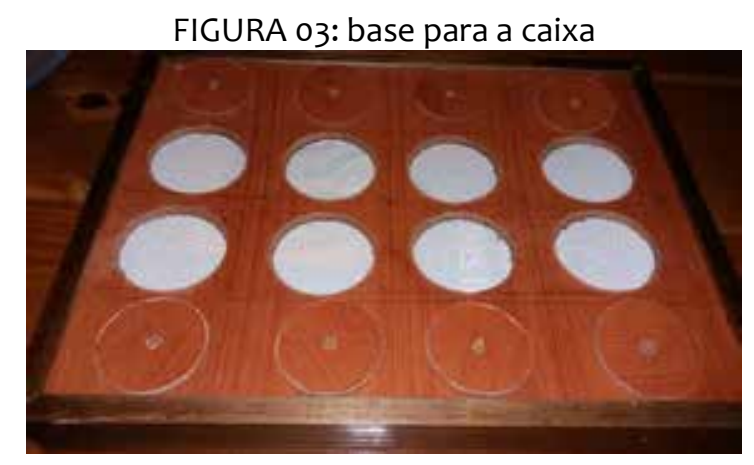

FONTE: os autores, 2020.

O material contempla, além dos oito espaços, sendo quatro de cores quentes e outros quatro de cores frias, legenda em braile removíveis, para mudança de disposição das cores. As cores quentes recebem aquecimento por meio de um dispositivo térmico. Já as cores frias, que não recebem o aquecimento, são isoladas das demais termicamente.

Depois de concluída a fase de preparação, a caixa foi vedada e, iniciou-se o trabalho na parte externa, sendo realizada a pintura da caixa (FIGURA 04a).

FIGURA 04: a) caixa pintada; b) com velcros e c) com etiquetas
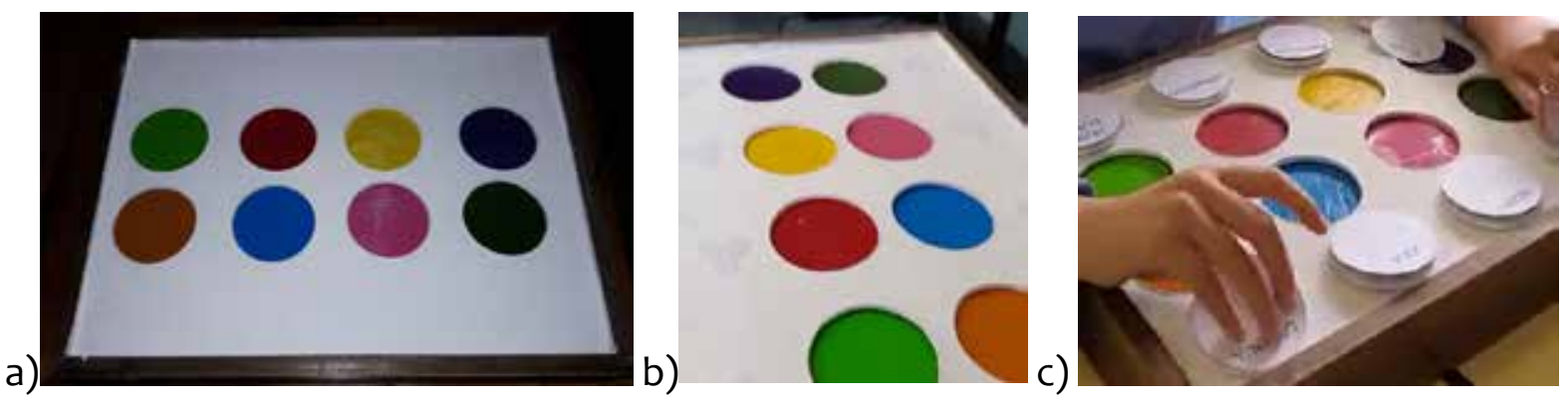

FONTE: os autores, 2020. 
As etiquetas foram fixadas com velcro em um círculo de madeira e este foi fixado na caixa, possibilitando assim sua retirada e colocação durante a exploração. (FIGURA 04 b)

Depois do material confeccionado iniciou-se a fase de testes e, novamente, a E1 se dispôs a participar. A exploração teste do material contribuiu para a percepção de que eram necessários alguns ajustes. O corte para identificar a posição correta da leitura do braile deixou o material mais acessível. A forma de fixação das etiquetas sobre as bases de madeira dificultava a adequada fixação, já que o velcro redondo estava centralizado, deixando instável a etiqueta, sendo assim, as etiquetas foram coladas sobre as bases de madeira, o que facilitou o manuseio.

Em seguida, foram colocadas etiquetas próximas a cada uma das cores com o nome da cor digitada em língua portuguesa e em braile (FIGURA 04C e FIGURA 05).

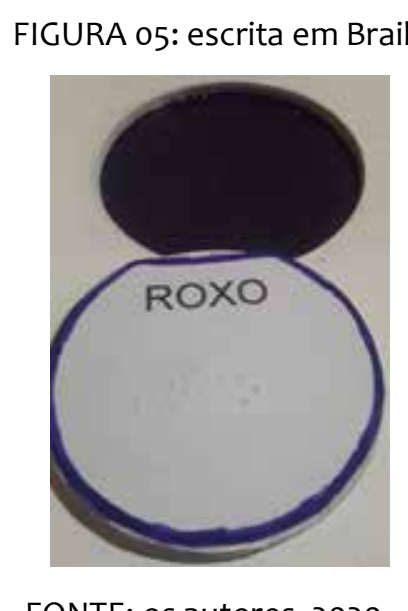

FONTE: os autores, 2020.

Além disso, foi colocado, no entorno da ficha com o nome da cor, uma linha da referida cor para o caso de estudantes que não soubessem ler, ficando conforme a Figura 06. 


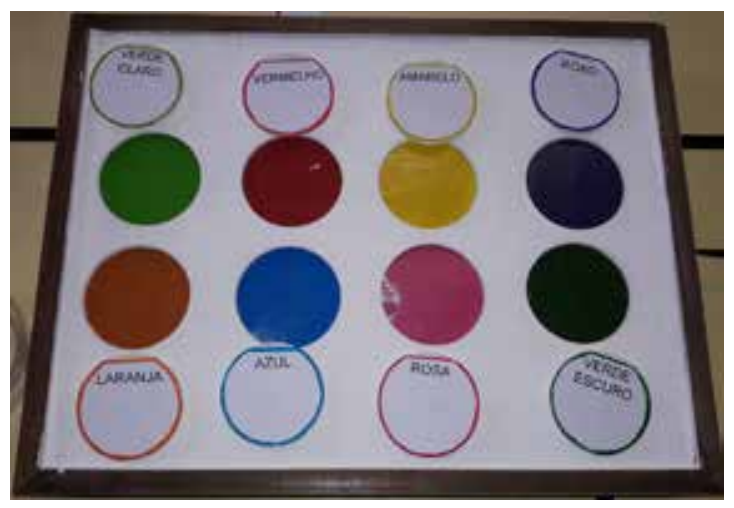

FONTE: os autores, 2020.

Para a confecção das etiquetas em braile, foi necessária a participação da Estudante 1, que possui a máquina de escrita em braile e ficou muito animada em poder contribuir na construção do material. Tal fato elucida como deve ser o trabalho realizado para a efetiva inclusão, pois como indica o Comitê sobre os Direitos das Pessoas com Deficiência da Organização das Nações Unidas (ONU)

As pessoas com deficiência geralmente não são consultadas na tomada de decisões sobre questões que são relacionadas ou que afetam suas vidas, e, ainda, as decisões são tomadas em seu nome. Nas últimas décadas, a importância de consultar pessoas com deficiência foi reconhecida devido ao surgimento de movimentos de pessoas com deficiência que exigem o reconhecimento e determinação de seus direitos humanos. O lema "nada sobre nós sem nós" traz voz à filosofia e à história do movimento pela defesa dos direitos das pessoas com deficiência, baseado no princípio da participação genuína. (ONU, 2018, p. 2, nossa tradução).

Depois da Caixa de Sensações concluída, iniciaram-se as propostas de exploração, com profissionais da escola que atendem a turma da Estudante 1, com a E1 e seus colegas. Além desses, alguns estudantes que frequentam a sala de recursos multifuncional também participaram de propostas com o material e os resultados estão apresentados na sequência.

\section{Resultados e análises}

Foi possível perceber que, a partir das diferenciadas propostas de exploração do material produzido, os estudantes envolvidos tiveram novos aprendizados.

Quanto à Estudante 1, ficou evidente seu aprendizado a respeito do tema abordado, pois apresentou resultados significativos a respeito da compreensão dos 
objetivos relacionados a disciplina de Artes Visuais, no que diz respeito à compreensão da temperatura das cores. Foi perceptível em sua fala que identifica, reconhece e utiliza em suas produções as cores de acordo com a temperatura:

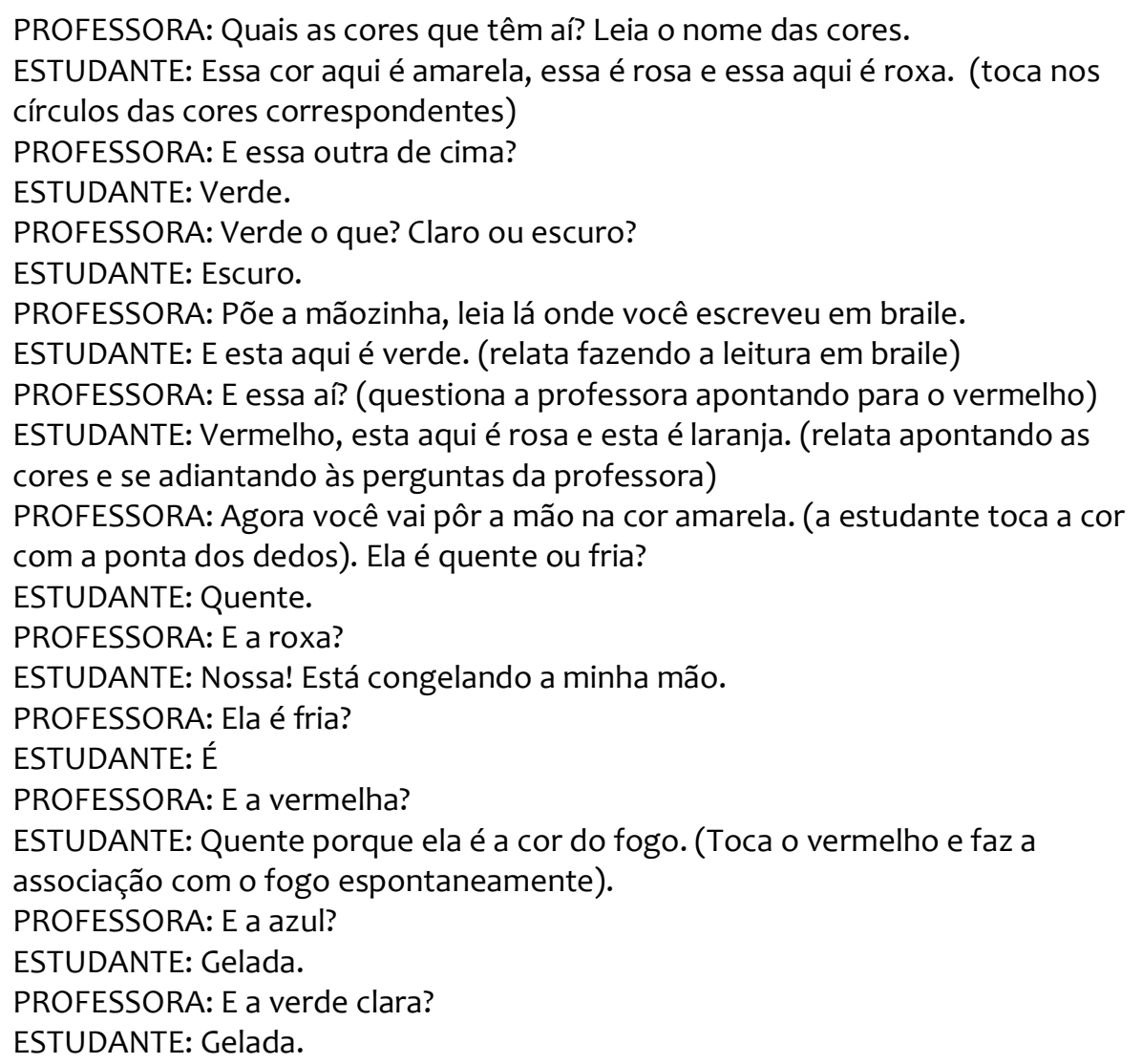

Com o relato da estudante foi possível perceber a associação que ela faz das cores quentes com elementos que emitem calor como o "fogo", exatamente como Ostrower cita em seu texto: "Assim, o vermelho e o amarelo são espontaneamente associados a calor, fogo, sol [...]”. (2013, p. 193).

PROFESSORA: Quais as cores que são quentes aí então?

ESTUDANTE: Rosa, vermelho, amarelo e laranja. (Relata apontando as cores corretamente) PROFESSORA: E quais as cores que são frias?

ESTUDANTE: Verde, azul e roxo.

PROFESSORA: Muito bem. Você gostou dessa caixa? ESTUDANTE: Gostei.

PROFESSORA: Da para perceber quais são as cores que tem aí? ESTUDANTE: Dá, eu tenho baixa visão e consigo enxergar só com um olho. PROFESSORA: E me diz uma coisa, está escrito em braile aí? ESTUDANTE: Sim PROFESSORA: Mostre para mim onde está escrito em braile. ESTUDANTE: Aqui. (aponta para uma etiqueta) PROFESSORA: O que está escrito aí? ESTUDANTE: Roxo. (faz a leitura em braile) PROFESSORA: Quem escreveu em braile? ESTUDANTE: Eu. (Responde orgulhosa) 
PROFESSORA: Você escreveu em braile? Muito bem!

A partir dessa exploração ficou evidente que a E1 compreendeu a diferença de sensações que as cores podem causar, mesmo com baixa visão pode experienciar pelo tato. Percebeu-se que a estudante usa além das pontas dos dedos, outras partes do corpo na identificação da sensação térmica. (FIGURA 07)

FIGURA 07: a) E1 realizando a leitura em Braile; b) identificando o local adequado para cada etiqueta; c)
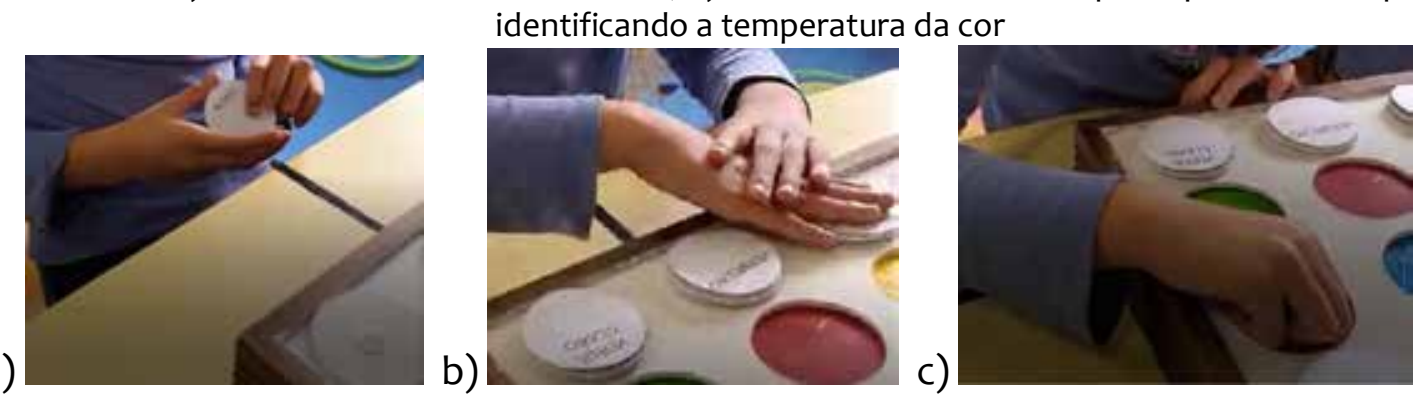

FONTE: os autores, 2020.

Para a identificação das cores, a leitura em braile ajudou, foi durante essa exploração que a estudante demonstrou a dificuldade de identificar a posição correta das fichas para a leitura, sendo assim, o material sofreu a primeira alteração. As fichas receberam um corte na parte superior para a identificação da posição correta para facilitar a leitura pelos participantes cegos ou com baixa visão. (Como já apresentado nas Figura 05 e 06)

Outra situação apontada pela estudante na fase de testes foi a posição do velcro sob as fichas que as deixava instáveis para leitura, dessa forma foi necessária mais uma alteração. Para melhorar a leitura em braile foi colado o velcro maior na peça toda, para facilitar a fixação. (FIGURA 08)

FIGURA 08: a) E1 realizando a leitura em Braile; b) E1 colocando as etiquetas nas cores correspondentes 
a)

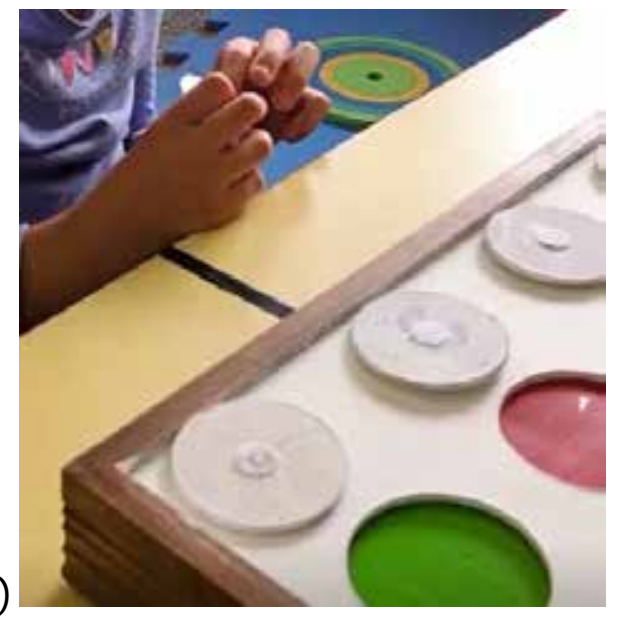

b)

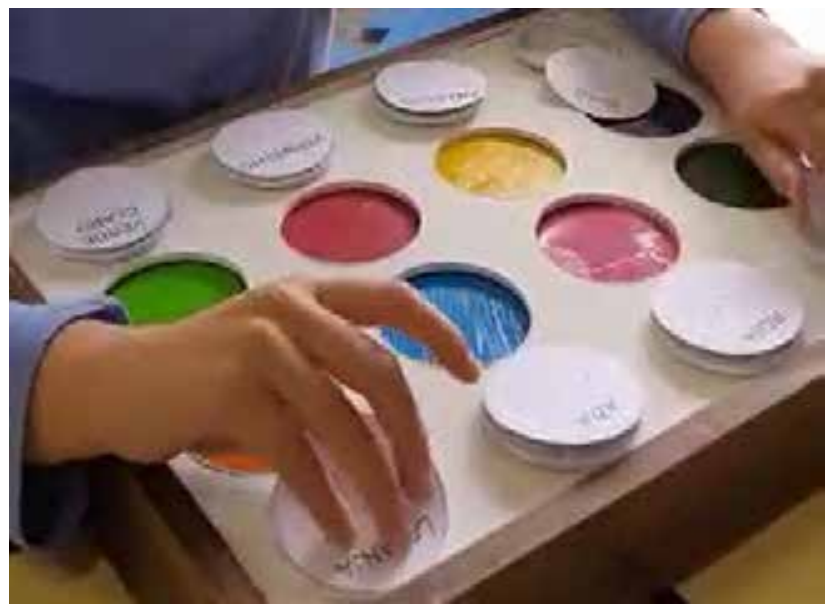

FONTE: os autores, 2020.

A exploração das fichas após as alterações facilitou tanto a leitura quanto a disposição das fichas no local adequado e na posição correta, como é possível verificar na caixa pronta, após todas as alterações.

\footnotetext{
PROFESSORA: Agora pegue outra ficha.

ESTUDANTE: Pode pegar qualquer uma?

PROFESSORA: Pode pegar qualquer uma, mas só que deixa eu colocar ela retinha. Que cor é essa?

ESTUDANTE: Azul

PROFESSORA: Azul, então coloque lá a cor azul, o retinho é para cima. Agora vai pegar outra, que cor é essa?

ESTUDANTE: Verde claro. (relatou já posicionando corretamente para a leitura e colando-a corretamente no local).
}

Depois da exploração individual, o material foi apresentado à turma durante uma aula em que a professora trabalhava com as características das cores.

A caixa foi explorada pelos estudantes videntes e a E1 estava atenta para auxiliar seus colegas, explicando como funciona a caixa e orientou os que tinham alguma dúvida ou dificuldade; contou que foi ela quem escreveu os nomes das cores em braile e aparentava estar muito feliz em ter participado da construção e teste do material que agora era explorado por todos.

A Figura 09 apresenta um dos estudantes videntes, Estudante 2, fazendo a relação das cores com as etiquetas e explorando a sensação térmica. 
a)

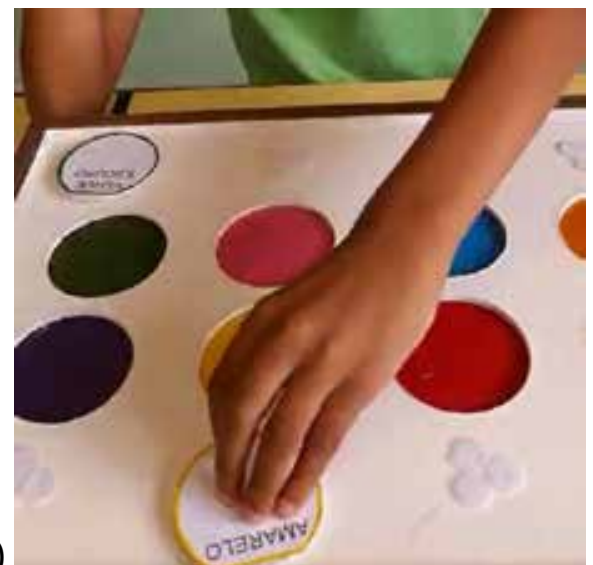

b)

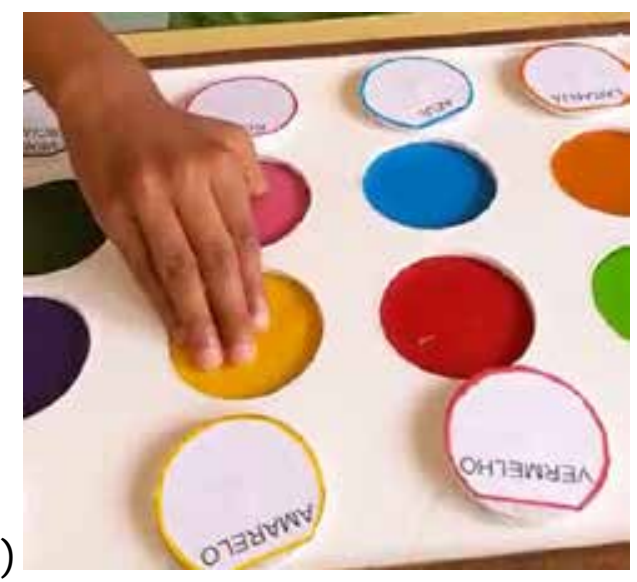

FONTE: os autores, 2020.

A professora que atende os alunos na sala de recursos multifuncionais da escola utilizou a caixa com um estudante autista, Estudante 3, que não reconhece e nomeia as cores sozinho, mas faz pareamento. Ao explorar o material ele se utilizou de uma estratégia diferente da proposta inicial, ou seja, ele relacionou as cores da caixa com as dicas coloridas do entorno das fichas, colocando as etiquetas sobre as cores correspondentes. Ficou muito satisfeito em completar o resultado com todas as cores, conforme Figura 10.

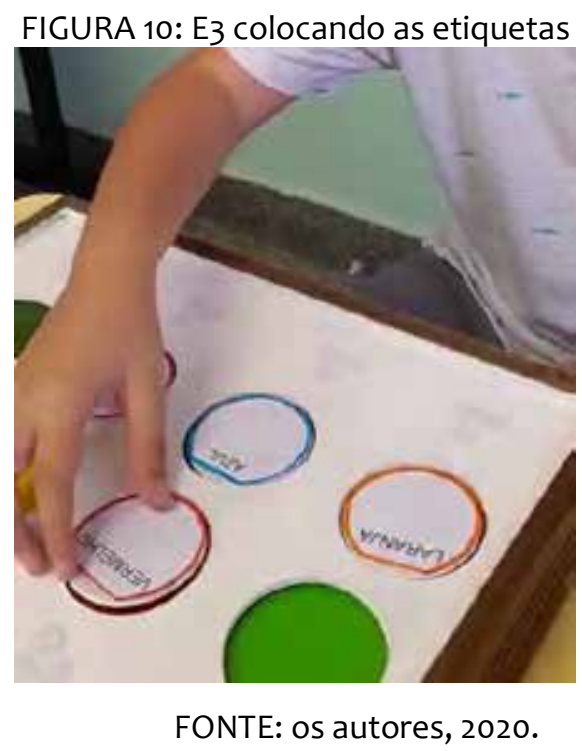

A exploração por diferentes públicos confirmou a afirmação de Zerbato e Mendes (2018, p. 150), pois, "na perspectiva do DUA, o mesmo material pode ser utilizado por todos da sala de aula, de modo a beneficiar outros estudantes na compreensão dos conteúdos ensinados.". 
Foi possível observar que o material desenvolvido contempla os princípios do DU, sendo igualitário, uma vez que todos os envolvidos puderam jogar; adaptável, pois, atendeu a todos os participantes de forma igualitária, sem nenhum prejuízo; óbvio, pois, no equipamento final com todas as alterações realizadas, o material atendeu as crianças sem deficiência, e crianças com autismo e com deficiência intelectual, bem como foi apreciado por profissionais, independendo de habilidades específicas; conhecido, pois atendeu crianças com baixa visão, com visão considerada normal - sendo vendadas ou não, com autismo e com deficiência intelectual. (GABRILLI, 2007)

Além disso, apresenta o princípio do conforto, por ser um equipamento de fácil transporte e necessita apenas de uma fonte de energia para seu funcionamento; sem esforço, uma vez que o participante só necessita tocar sobre os locais indicados para realizar a proposta, sendo que, em possíveis casos de participantes com ausência dos membros superiores, outras partes do corpo podem ser utilizadas para a exploração, e abrangente, pois consiste em uma caixa de 40 X $50 \mathrm{~cm}$, com dois quilos aproximadamente, que pode ser colocada sobre qualquer mesa ou suporte. (GABRILLI, 2007)

Ficou evidente com esta pesquisa que um professor precisa de apoio e parcerias com colegas para colocar em prática algumas possibilidades inovadoras, bem como o apoio e incentivo da direção e equipe pedagógica da instituição, conforme defendem Zerbato e Mendes:

As modificações no ato de ensinar não são tarefas fáceis e simples de serem executadas, nem ao menos é possível que o professor do ensino comum, sozinho, as realize. É necessário que ele conte com uma rede de profissionais de apoio, recursos suficientes, formação e outros aspectos necessários para a execução de um bom ensino. Inclusão escolar não se faz somente dentro da sala de aula. (ZERBATO; MENDES; 2018, p. 148).

No caso desta pesquisa isso ficou claro, pois foram vários professores que, envolvidos com os alunos investigados, participaram efetivamente da proposta, observando, dando sugestões e realizando a exploração do material com os estudantes.

\section{CONSIDERAÇÕES FINAIS}

A inclusão nas escolas é uma realidade que precisa ser encarada com seriedade por toda a sociedade, mas, principalmente, pelos profissionais da educação. A busca por 
novas metodologias e por recursos mais abrangentes podem possibilitar o acesso à aprendizagem para todos os estudantes e auxiliar o professor em seu planejamento. Uma forma de se chegar a esse resultado é utilização de recursos que realmente efetivem a inclusão, eliminando as barreiras metodológicas para a aprendizagem e colabora para novas formas de pensar o processo educativo democrático e abrangente.

Nesse contexto a Caixa de Sensações buscou universalizar o atendimento aos estudantes, sejam com ou sem deficiência, atendendo os estudantes com qualidade (BRASIL, 2014).

Quanto aos princípios do DU indicado por Gabrilli (2007), é possível observar que a Caixa de Sensações é um produto que possui forma e tamanho que possam ser utilizados em mobiliário utilizado pelos estudantes, desta forma, o material cumpre o requisito abrangente do DU. É igualitário, pois pode ser utilizado por estudantes com capacidades diferentes: experimentado e elaborado com a ajuda da estudante com baixa visão; estudantes que frequentam as aulas de Arte na mesma turma do ensino regular da estudante com baixa visão, por meio de uma proposta de exploração tátil e visual sobre a temperatura das cores; estudantes da sala de recursos multifuncionais com autismo e deficiência intelectual em que o uso não se restringiu ao conteúdo proposto sobre a temperatura das cores, pois os estudantes que não sabem ler fizeram pareamento das cores das fichas com as cores da caixa, encaixando-as nos espaços adequados. Essa ação possibilitou a reflexão por parte dos professores de que o mesmo material pode ter diferentes possibilidades de uso.

Ao ser concebido com as intervenções da Estudante 1, o material possui adaptações necessárias para a compreensão dos conceitos de Artes Visuais por estudantes que possuam, ou não, deficiência visual. Ainda, a inclusão da simbologia Braile torna o material de fácil comunicação e compreensão de seu objetivo, trazendo informações perceptíveis.

Por trazer sistema de aquecimento das placas de cores quentes o material desenvolvido é óbvio em sua experimentação, não sendo necessários conhecimentos além da idade dos estudantes, visto que as sensações são percebidas pelos indivíduos em suas idades mais tênues. Ainda, o aquecimento é realizado de tal forma que se torne seguro, com quantidade de calor suficiente para diferenciar a sensação de uma cor quente para uma cor fria. 
Como as placas coloridas possuem formas circulares, exigem pouco esforço de quem as manuseia, sobretudo de pessoas com deficiência de mobilidade, pois geralmente encaixa com maior facilidade.

Assim, por cumprir os princípios do DU e ser um material didático, visando à compreensão de conceitos escolares/científicos, a Caixa de Sensações é classificada como um produto na perspectiva do Desenho Universal para Aprendizagem, pois este material didático

visa proporcionar uma maior variedade de opções para o ensino de todos, considerando a diversidade da sala de aula, valorizando como eles expressam seus conhecimentos e como estão envolvidos e motivados para aprender mais. (ZERBATO; MENDES, 2018, p. 149)

A utilização da Caixa de Sensações proporcionou os três princípios do DUA (ROSE; MEYER, 2002): princípio de engajamento - no momento em que a E1 explica o funcionamento do material, ela se torna parte do grupo, ocorrendo a total inclusão escolar; princípio da representação - apresenta por diferentes formas os mesmos conceitos, seja pelas cores das placas, pelas classificações escritas em nosso alfabeto e código Braile e, também, as sensações proporcionadas pelas placas; princípio da ação e expressão - a Caixa de Sensações, por ser um material manipulável, é um modelo flexível de demonstração que fornece informações sobre aprendizagem do estudante em tempo real na prática docente-estudante.

No contexto da inclusão escolar, os profissionais necessitam ser flexíveis em suas ideias e concepções, buscando pensar como o "outro", sentido as aflições do "outro", melhorando suas práticas e o desenvolvimento dos recursos para a utilização do "outro". Isso é claramente verificado no desenvolvimento da Caixa de Sensações, pois a ideia inicial foi sofrendo alterações para melhora do equipamento, o qual se mostrou eficiente para o objetivo pensado inicialmente, e foi utilizado com outras propostas para atender as necessidades de diferentes públicos, tanto na sala de aula do ensino regular, como na sala de recursos multifuncionais. Com isso, as crianças que participaram da proposta conseguiram desenvolver novas aprendizagens referentes às cores e ao conceito de temperatura das cores, demonstraram maior interesse pela proposta de explorar sensorialmente as cores quentes e frias.

Além dos objetivos iniciais propostos foi possível verificar que a Caixa de Sensações pôde ser utilizada para trabalhar outros conceitos como a relação das cores 
das fichas com as cores da caixa; leitura do nome das cores em Língua Portuguesa pelos estudantes videntes e em Braile pela estudante com baixa visão, bem como, o estudo de cores primárias e secundárias. Além disso, foi uma ação pedagógica que envolveu diversos professores da escola na busca de soluções para a melhor apresentação do material aos estudantes.

Portanto, é evidente que esta pesquisa, pautada na observação do cotidiano escolar, contribui e muda o paradigma da educação seletiva para um modelo que atende as mais diferentes necessidades educativas por meio de um material didático concebido na perspectiva do Desenho Universal para Aprendizagem.

\section{REFERÊNCIAS}

BRASIL. Ministério da Educação. Lei de Diretrizes e Bases da Educação Nacional, LDB 4.024, de 20 de dezembro de 1961.

BRASIL. Ministério da Educação. Lei de Diretrizes e Bases da Educação Nacional, LDB 5.692, de 11 de agosto de 1971.

BRASIL. Constituição da República Federativa do Brasil. Brasília: imprensa oficial, 1988.

BRASIL. Ministério da Educação. Secretaria de Educação Especial. Lei №. 7.853, de 24 de outubro de 1989.

BRASIL. Estatuto da Criança e do Adolescente no Brasil. Lei n. 8.069, de 13 de julho de 1990.

BRASIL. Declaração Mundial sobre Educação para Todos: plano de ação para satisfazer as necessidades básicas de aprendizagem. UNESCO, Jomtiem/Tailândia, 1990.

BRASIL. Declaração de Salamanca e linha de ação sobre necessidades educativas especiais. Brasília: UNESCO, 1994.

BRASIL. Ministério da Educação. Secretaria de Educação Especial. Política Nacional de Educação Especial. Brasília: MEC/SEESP, 1994.

BRASIL. Ministério da Educação. Lei de Diretrizes e Bases da Educação Nacional, LDB 9.394, de 20 de dezembro de 1996.

BRASIL. Ministério da Educação. Secretaria de Educação Especial. Decreto № 3.298, de 20 de dezembro de 1999. 
BRASIL. Ministério da Educação. Secretaria de Educação Especial. Diretrizes Nacionais para a Educação Especial na Educação Básica. Secretaria de Educação Especial MEC/SEESP, 2001.

BRASIL. Ministério da Educação. Lei № 10.172, de 09 de janeiro de 2001. Aprova o Plano Nacional de Educação e dá outras providências.

BRASIL. Decreto $N^{\circ} 3.956$, de 8 de outubro de 2001. Convenção Interamericana para a Eliminação de Todas as Formas de Discriminação contra as Pessoas Portadoras de Deficiência. Guatemala: 2001.

BRASIL. Ministério da Educação. Secretaria de Educação Especial. Programa Educação Inclusiva: direito à diversidade. Brasília, 2006.

BRASIL. Ministério da Educação. Planejando a Próxima Década. Conhecendo as 20 Metas do Plano Nacional de Educação. Ministério da Educação/Secretaria de Articulação com os Sistemas de Ensino (MEC/Sase): Brasília, DF, 2014.

COSTA, Robson Xavier da; ARAÚJO JÚNIOR, Aarão Pereira de. Artes visuais \& inclusão: maquetes táteis de obras de arte a baixo custo. Revista GEARTE, Porto Alegre, v. 5, n. 1, jan./abr. 2018. p. 145-157.

CURITIBA. Diretrizes curriculares para a educação municipal de Curitiba. Ensino Fundamental, v. 3. Curitiba, PR, 2006. Disponível em: http://www.cidadedoconhecimento.org.br/cidadedoconhecimento/downloads/arquivos/3 010/download3010.pdf. Acessado em 21 de fev. de 2020.

DAMIANI, Magda Floriana. et al. Discutindo pesquisas do tipo intervenção pedagógica. Cadernos de Educação, Pelotas, n. 45, jul./ago. 2013, p. 57-67. Disponível em: <https://periodicos.ufpel.edu.br/ojs2/index.php/caduc/article/view/3822/3074> Acesso em: 11 jan. 2020.

GABRILLI, Mara. Desenho Universal: um conceito para todos. Disponível em: https://www.maragabrilli.com.br/wp-content/uploads/2016/01/universal_web-1.pdf.

Acesso em 23 de jan. de 2020.

ONU - Organização das Nações Unidas. Comité sobre los derechos de las personas con discapacidad, $2018 . \quad$ Disponível em: https://tbinternet.ohchr.org/_layouts/15/treatybodyexternal/Download.aspx?symbolno=C RPD/C/GC/7\&Lang=en. Acesso : 13 de fev. de 2020.

OSTROWER, Fayga. Universos da arte. Campinas, SP: Editora da Unicamp, 2013, 510p.

ROSE, David H.; MEYER, Anne. Teaching every student in the digital age: universal design for learning. Association for Supervision and Curriculum Development, Alexandria, 2002. $216 \mathrm{p}$. 
VALENTE, Tamara da Silveira. Da inclusão do direito ao direito à inclusão. In: GUÉRIOS, Ettiène; STOLTZ, Tania (orgs.). Educação em direitos humanos: qual o sentido? ljuí: Ed. Unijuí, 2015. p. 169-201.

ZERBATO, Ana Paula; MENDES, Enicéia Gonçalves. Desenho Universal para aprendizagem como estratégia de inclusão escolar. Educação Unisinos 22, p. 147-155, abril-junho 2018.

Recebido em: 28/02/2020

Parecer em: 15/10/2020

Aprovado em: 28/12/2020 